\title{
О ПЕРСПЕКТИВАХ ПРЕЦИЗИОННОГО УПРАВЛЕНИЯ ПРОДУКТИВНОСТЬЮ ПШЕНИЦЫ В УСЛОВИЯХ СЕВЕРНОГО КАЗАХСТАНА *
}

\author{
Б.Р. ИРМУЛАТОВ1, К.К. АБДУЛЛАЕВ 1 , А.А. КОМАРОВ ${ }^{凶}$, В.В. ЯКУШЕВ²
}

Повышение урожайности и качества пшеницы в условиях Республики Казахстан может быть достигнуто посредством реализации селекционного потенциала культуры. Для решения этой задачи определяющее значение имеют инновационные агротехнологические подходы, включающие систему точного земледелия (ТЗ). Учитывая значительную площадь Казахстана, одним из первых элементов внедрения Т3 становится оценка состояния обширных территорий этой страны с использованием современных технологий дистанционного зондирования Земли (ДЗ3). В настоящей работе впервые в условиях Северного Казахстана были реализованы приемы прецизионного управления продуктивностью яровой пшеницы. Цель работы - оценить перспективы использования системы точного земледелия в условиях Северного Казахстана и на этом основании предложить алгоритм перехода от пассивных мониторинговых мероприятий к активным управляющим прецизионным приемам повышения продуктивности яровой пшеницы. Исследования проводили на специализированном опытном полигоне точного земледелия (ТОО НПЦ зернового хозяйства им. А.И. Бараева) в условиях вегетационных сезонов 2019-2020 годов. Основным объектом были высокопродуктивные сорта яровой пшеницы (Triticum vulgare L.) местной селекции Шортандинская 95 и Астана. На первом этапе поля полигона (темно-каштановые почвы) были обследованы по основным агрохимическим показателям с помощью наземного мобильного комплекса. Детализацию оценки плодородия почв осуществляли по схемам (сеткам обследования) с размерами элементарных участков 1, 5 и 25 га. Полученные данные использовали для выявления внутриполевой неоднородности и расчета доз удобрений для дифференцированного внесения. На втором этапе оценивали состояние посевов по космическим снимкам, сделанным спутниками группы Sentinel-2, и аэрофотоснимкам, полученным с помощью беспилотных летательных аппаратов. Диагностику развития растений по фенофазам проводили на основании нормализованного вегетационного индекса (normalized difference vegetation index, NDVI), а конечный результат оценивали по электронным картам урожайности. На третьем этапе осуществляли статистическую оценку полученных данных с использованием пакета прикладных программ Stat и Microsoft Excel 2010 и программного обеспечения AGROS-1 (версия 2.09-2.11/1993-2009). Основные удобрения вносили припосевным и поверхностным способами. Также проводили некорневые подкормки. В экспериментах применяли полимерные удобрения Витанолл-NP (1 л/га) и Витанолл-микро (1 л/га) (ООО «Агромаркет-24», Россия), комплексное хелатное КХМ (2 л/га) (ФГБНУ Агрофизический НИИ, Россия) и гуминовое Стимулайф (0,3 л/га) (ООО «Агрофизпродукт», Россия). Установлено, что только одна агрохимическая неоднородность поля частично нивелировалась дифференцированным внесением элементов питания. В засушливых условиях Казахстана установлено доминирующее влияние на продуктивность яровой пшеницы параметров почвенного плодородия, связанных с запасом и распределением почвенной влаги (почвенно-ландшафтно-гидрологических условий). По изменению агроландшафтных условий, которые определяются уклоном местности, удалось оценить распределение водотоков, характеризующих запас продуктивной влаги в той или иной части поля. На основании данных ДЗ3 и сопряженных наземных измерений предложен алгоритм перехода от констатации полученных данных к оперативному управлению биопродукционным процессом растений. При этом чем более детализирован был анализ данных, тем выше оказывалась результативность. Так, прибавка урожайности при сетке 5 га была чуть меньше $10 \%$, а при сетке 1 га - в 2 раза больше. Показана тесная корреляционная связь между урожайностью и NDVI: коэффициент корреляции по трансекте склона составлял $r=0,64-0,99$, поперек поля $-r=0,62-0,98$. Получена значительная прибавка урожая как за счет дифференцированного внесения минеральных удобрений (на 9,5\% по сетке 5 га и на 19,2 \% по сетке 1 га), так и благодаря своевременным некорневым подкормкам (на 15$22,3 \%)$. В целом данные экспериментальных исследований свидетельствуют о перспективности применения Т3 в управлении продукционным процессом яровой пшеницы в условиях Северного Казахстана.

\footnotetext{
* Работа осуществлялась в рамках научно-технической программы, выполняемой ТОО «Научно-производственный центр зернового хозяйства им. А.И. Бараева»: «Трансферт и адаптация технологий по точному земледелию при производстве продукции растениеводства по принципу демонстрационных хозяйств (полигонов)» в Акмолинской области».
} 
Ключевые слова: яровая пшеница, северный Казахстан, точное земледелие, дистанционное зондирование Земли, агроландшафт, почвенное плодородие, почвенная влага.

Республика Казахстан - один из ведущих мировых экспортеров высококачественной пшеницы. Вместе с тем урожайность мягкой пшеницы в Казахстане в среднем составляет всего 10-15 ц/га, что обусловлено не только природно-климатическими факторами, но и несовершенством агротехнологий. Повышение урожайности и качества пшеницы может быть достигнуто посредством реализации ее селекционного потенциала $(1,2)$, обеспечивающего в том числе устойчивость к патогенам (3). Ранее было показано, что наряду с селекционными достижениями определяющее значение имеют инновационные агротехнологические подходы, включающие систему точного земледелия (Т3) $(4,5)$. Однако технологии Т3, успешно реализованные в Российской Федерации (4) и других странах $(6,7)$, требуют адаптации к условиям Северного Казахстана. Простое копирование или тиражирование системы Т3, ранее применяемой в гумидном климате, неприемлемо, когда речь идет о специфических засушливых условиях аридного климата.

Внедрение ТЗ в условиях Казахстана начато сравнительно недавно. С 2018 года в ТОО НПЦ зернового хозяйства им. А.И. Бараева разрабатывается специализированная программа «Трансферт и адаптация технологий по точному земледелию при производстве продукции растениеводства по принципу демонстрационных хозяйств (полигонов) в Акмолинской области». Научные исследования сосредоточены на специализированном полигоне Т3 площадью 3000 га, где с 2019 года проводятся прецизионные эксперименты. Одним из первых элементов внедрения точного земледелия в Казахстане (с учетом его протяженности) становится оценка состояния зон возделывания сельскохозяйственных растений с использованием современных технологий дистанционного зондирования Земли (Д33) $(8,9)$. На основе Д33 в настоящее время решаются многочисленные задачи, включающие прогнозную и фактическую оценку состояния и урожайности яровых культур на значительных территориях $(10,11)$, в том числе с оценкой площадей не только культивируемых растений, но и доли аборигенных видов $(12,13)$.

Для идентификации ДЗ3 требуется привязка к условиям местности, а также связь во времени и пространстве с наземными исследованиями, проводимыми с учетом неоднородности состояния почвенного покрова, что может быть реализовано только в прецизионных исследованиях. Кроме того, Д3З обеспечивает типичные мониторинговые наблюдения, направленные на оценку, анализ и лишь в какой-то мере - на прогноз состояния почв и растений $(4,14)$.

В настоящей работе впервые в условиях Северного Казахстана были реализованы приемы прецизионного управления продуктивностью яровой пшеницы. Показано, что при более детализированном анализе данных (степень прецизионности по сетке 1, 5 и 25 га) результирующая по урожайности повышалась, что связано с более точным дифференцированным использованием удобрений. Выявлено, что в засушливых условиях Казахстана более важное значение имеют почвенно-ландшафтно-гидрологические факторы, связанные с запасом и распределением почвенной влаги. С использованием ДЗ3 и нормализованного вегетационного индекса (normalized difference vegetation index, NDVI) установлена тесная корреляционная связь между дистанционными данными и картой урожайности. Кроме того, NDVI, определяемый с помощью беспилотных летательных 
аппаратов, отличался по информативности и оперативности от спутниковых снимков. На полигоне точного земледелия с помощью наземных и сопряженных Д33 наблюдений удалось оперативно выявлять зоны депрессии развития растений в неоднородном пространстве поля, что обеспечило возможность своевременно проводить необходимую коррекцию роста и развития растений с помощью некорневых подкормок.

Цель работы - оценить перспективы использования системы точного земледелия в условиях Северного Казахстана и на этом основании предложить алгоритм перехода от пассивных мониторинговых мероприятий к активным управляющим прецизионным приемам повышения продуктивности яровой пшеницы.

Методика. Исследования проводили на типичных для Северного Казахстана темно-каштановых почвах и южных карбонатных черноземах в условиях вегетационных сезонов 2019-2020 годов (специализированный опытный полигон точного земледелия (ТОО НПЦ зернового хозяйства им. А.И. Бараева). Основным объектом были высокопродуктивные сорта яровой пшеницы (Triticum vulgare L.) местной селекции. Сорт Шортандинская 95 (улучшенная), разновидность лютесценс, выведен методом ступенчатой гибридизации посредством массового отбора из гибридной популяции [(Пиротрикс $28 \times$ Джастин) $\times$ Целинная 21] $\times$ (Целинная $60 \times$ Лютесценс 57/76). Сорт среднепозднего типа, вегетационный период 95100 сут. Сорт Астана, разновидность лютесценс, выведен методом гибридизации (линия Лютесценс И-2959 × Целинная 90), среднераннего типа созревания, вегетационный период 80-84 сут.

Рост и развитие растений оценивали как с помощью традиционных наземных наблюдений, так по сопряженным с ними данным дистанционного зондирования Земли.

Предварительно на полигоне точного земледелия определяли параметры плодородия почв посредством детального агрохимического обследования по общепринятой методике, а в части вариантов - по 1-, 5- и 25гектарной сетке. При этом на полях с сеткой оценки 1 и 5 га применялась технология точного земледелия с переменным нормированием внесения удобрений, а на полях с сеткой 25 га - традиционная технология. Почвенные образцы отбирали автоматическим буром Wintex 3000 («Wintex Agro», Дания) с использованием мобильного комплекса с GPS-привязкой по диагональному маршруту для каждой ячейки взятия почвенной пробы. Полученные данные использовали для выявления внутриполевой неоднородности и расчета доз удобрений для их дифференцированного внесения.

Состояние растений оценивали по космическим снимкам, используя нормализованный вегетационный индекс (normalized difference vegetation index, NDVI) $(8,9)$. На основании детального изучения различных вегетационных индексов ранее были выделены наиболее информативные показатели, имеющие пространственное разрешение 30 м (15). Мониторинг спутниками группы Sentinel-2 осуществлялся с помощью сервиса LandViewer (https://eos.com), который позволяет обрабатывать и анализировать изображения в режиме реального времени. Также учитывали данные беспилотных летательных аппаратов (БПЛА) (16) Геоскан 201 Агро (ООО «Геосторойизыскания», Россия), оборудованных двумя камерами - фотокамерой RGB и модифицированной инфракрасной (ИК) камерой. Данные с первой использовались для создания ортофотоплана, карты высот, 3D модели, со второй - для карт NDVI.

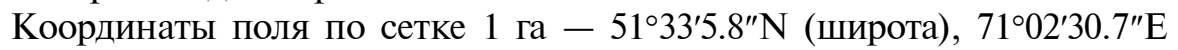

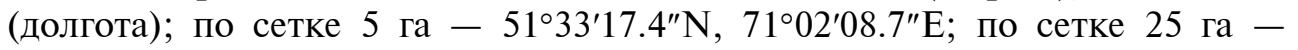


$51^{\circ} 33^{\prime} 14.2^{\prime \prime} \mathrm{N}, 7^{\circ} 03^{\prime} 25.1^{\prime \prime}$ Е. По кластерным секторам (по склону поля) при постоянной долготе 71 $02^{\prime} 30.7^{\prime \prime}$ Е координаты для сектора $1-51^{\circ} 33^{\prime} 15.8^{\prime \prime} \mathrm{N}$, для сектора 2 - 51 $33^{\prime} 54.7^{\prime \prime} \mathrm{N}$, для сектора $3-51^{\circ} 32^{\prime} 43.7^{\prime \prime} \mathrm{N}$. На полях с дифференцированным внесением удобрений по сетке 1 и 5 га возделывалась яровая пшеница сорта Шортандинская 95, на полях со стандартной технологией - пшеница сорта Астана. Все поля располагались в пределах одной почвенной разности на темно-каштановых почвах.

Управляющие приемы точного земледелия были реализованы посредством дифференцированного применения основных удобрений двумя способами - при припосевном внесении удобрений в рядки одновременно с посевом семян с использованием комплекса Bourgault («Bourgault Industries Ltd.», Канада) и поверхностным методом с помощью распределителя твердых сыпучих удобрений Amazone ZA-M («AMAZONEN-WERKE H. Dreyer GmbH \& Co. KG», Германия). Оба эти комплекса были оснащены управляющей бортовой электроникой и GPS-приемниками, что позволяло контролировать внесение удобрений с заданной точностью.

Корректирующее управление биопродукционным процессом осуществляли за счет некорневых подкормок. Подкормки проводили раствором из расчета 50-100 л баковой смеси на 1 га при помощи оборудования для внесения жидких удобрений (самоходный опрыскиватель John Deere m 4030, «John Deere», США). В экспериментах применяли полимерные удобрения Витанолл-NP (1 л/га) и Витанолл-микро (1 л/га) (OOO «Агромаркет-24», Россия) (25), комплексное хелатное удобрение КХМ (2 л/га) (ФГБНУ Агрофизический НИИ, Россия) и гуминовое удобрение Стимулайф (0,3 л/га) (ООО «Агрофизпродукт», Россия) (26). Оперативную коррекцию урожайности проводили в критические фазы онтогенеза, которые оценивали с помощью ДЗ3.

Статистический анализ проводили в пакетах прикладных стандартных программ Stat и Microsoft Excel 2010 и с помощью программного обеспечения AGROS-1 (версия 2.09-2.11/1993-2009). Достоверность результатов полевых экспериментов на основании дисперсионного, корреляционного и вариационного анализа определяли согласно методике полевого опыта (17). Данные Д3З оценивали на основании кластерного анализа $(18,19)$ и анализа временных рядов $(20,21)$, а также динамики NDVI за вегетационный период по каждому полю (22-24). Кривые динамики NDVI по срокам анализа сглаживали в режиме дисперсии. Данные были представлены в графическом виде (21). При этом использовали программное обеспечение для точного земледелия FieldRoverII («Site-Specific Technology Development Group, Inc.», США) и SMS Advanced («Ag Leader Technology, Inc.», США), а также собственные разработки «Agro-Network Technologies» (Казахстан) и АФИ ГИС (Россия).

Результаты. Отличительная особенность наших исследований - их прецизионный характер, что впервые позволило перейти от оценки наблюдаемых явлений к оперативному применению средств коррекции урожая.

Использование Д3З в условиях Казахстана далеко не ново. Ранее национальным центром космических исследований и технологий была внедрена информационно-аналитическая система АгроГИС, адаптированная для решения задач космического мониторинга производства зерна в Казахстане (27). На основании данных EOS MODIS (Moderate Resolution Imaging Spectroradiometer) А.Г. Тереховым представлены эмпирические зависимости между урожайностью и различными спектральными характеристиками полей для незерновых (28) и зерновых культур (29) в течение 
ряда сезонов. Получены результаты, подтверждающие тесные связи между вегетационными индексами и урожайностью возделываемых культур (2729). Однако эти и другие мониторинговые исследования в условиях Казахстана проводились на больших территориях, поэтому носили скорее статистически обобщающий и прогнозный характер и не детализировали данные по каждому полю в отдельности в аспекте их мозаичности по плодородию и агроландшафтным особенностям. При этом до сих пор не учитывалась внутриполевая пестрота (неоднородность) каждого поля, что можно реализовать только с помощью технологии прецизионного земледелия.

Для выявления внутриполевой неоднородности разработаны методы, основанные преимушественно на геостатистике, однако для дешифровки Д3З в неоднородном пространстве поля существует не так много подходов. Основываясь на многолетних исследованиях Агрофизического научно-исследовательского института (АФИ) по внедрению технологии точного земледелия, мы разработали алгоритм перехода от типичных мониторинговых исследований к новым управляющим приемам возделывания пшеницы в неблагоприятных засушливых условиях Казахстана. Так, для выделения границ внутриполевой неоднородности предложен новый прецизионной подход, базирующийся на сопряженной обработке ДЗ3 и наземной прецизионной информации $(4,15)$, впервые реализованный в условиях Северного Казахстана (30).

На полигоне точного земледелия проводилась детальная оценка неоднородности состояния почвенного покрова по основным агрохимическим показателям. Была сформирована сеть из 159 элементарных участков площадью по 1 га, а также сеть полигонов по 5 и 25 га. По основным агрохимическим характеристикам выявлена сравнительная неоднородность массивов. Так, в сетке 1 га при среднем содержании $\mathrm{N}-\mathrm{NO}_{3} 15,2$ мг/кг коэффициент вариации $(C v)$ составил 65 \%, для $\mathrm{P}_{2} \mathrm{O}_{5}(27,2$ мг/кг) $-27 \%$, а по $\mathrm{K}_{2} \mathrm{O}(733$ мг/кг) - $21 \%$. Увеличение размера элементарного участка при определении самого вариабельного показателя - содержания нитратного азота в почве приводило к снижению коэффициента вариации. В то же время при уменьшении размера элементарного участка снижался показатель неоднородности по подвижному фосфору.

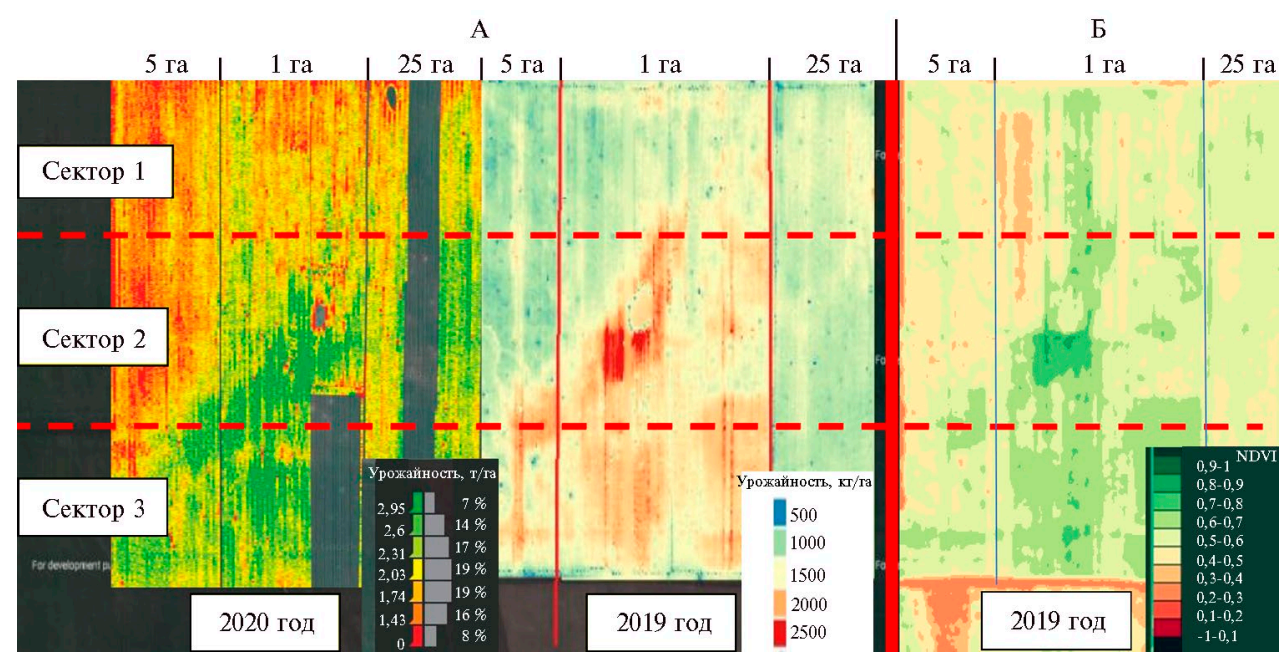

Рис. 1. Сопряженные данные наземного зондирования (карты урожайности яровой пшеницы Triticum vulgare L.) (A) и дистанционного зондирования Земли (нормализованный вегетационный индекс, NDVI) (Б) с дифференциацией по сеткам оценки 5, 1 и 25 га и кластерам (секторы 1-3) в разные годы (ТОО НПЦ зернового хозяйства им. А.И. Бараева, Казахстан). 
Особый практический интерес представляли данные, служащие информационной основой для последующих расчетов и анализа, - электронная карта урожайности с сеткой 1, 5 и 25 га (рис. 1). На каждом поле были зоны (выделены как секторы, или кластеры) с явно низкой и более высокой урожайностью. Эти кластеры отчетливо проявлялись по данным карты урожайности за вегетационный период 2019 года, а также независимо и однозначно - в условиях 2020 года. Более того, кластер проявлялся как обособленная зона неоднородности поля, идентифицируемая не только по карте урожайности, но также в сопряженной оценке с ДЗ3.

Результаты, полученные в засушливых условиях Казахстана в 2019 году и подтвержденные в условиях вегетационного сезона 2020 года, позволили выявить доминирующее влияние на продуктивность культуры скоpeе не типичных агрохимических параметров почвенного плодородия, а иных, связанных с запасом и распределением почвенной влаги (почвенноландшафтно-гидрологических). Ранее (30) мы, как и другие исследователи (4-6), акцентировали внимание именно на параметрах агрохимической неоднородности поля и с помощью дифференцированного внесения минеральных удобрений пытались устранить дефицит питания. Поэтому в результате кластерного и детального анализа урожайности по каждой ячейке полигона для сетки 1 га не удалось выявить сколько-нибудь значимой взаимозависимости с параметрами почвенного плодородия.

Вместе с тем в настоящем эксперименте была установлена очень тесная связь между урожайностью и NDVI. Вдоль длинного гона поля по направлению рядков посева пшеницы коэффициент корреляции между урожайностью и NDVI по трансекте составлял $r=0,64-0,99$ (выборка из 9 рядов с ячейкой 1 га), поперек поля - 0,62-0,98 (выборка из 18 рядов с ячейкой 1 га). Однако на основании полученных результатов, как и данных других исследователей $(30,31)$, нам не удалось выделить фактор, определяющий нарастание урожайности по кластерам поля, неоднородного в направлении с его северной части (сектор 1) к южной (сектор 3).

Было установлено, что только одна агрохимическая неоднородность экспериментального поля частично нивелировалась дифференцированным внесением элементов питания. Эта неоднородность отчетливо проявилась при детальном учете данных по урожайности. Разделив поле по зонам неоднородности массива на три сектора (рис. 2), можно отметить, что средняя урожайность за 2019 год в верхней части поля (сектор 1) составляла 12,8 ц/га, в центре (сектор 2) - 15,4 ц/га, в нижней части 18,2 ц/га (сектор 3). В условиях 2020 года эта тенденция сохранилась, однако средняя урожайность оказалась несколько выше. Было установлено, что с повышением степени прецизионности исследований (сетки 25, 5 и 1 га) как общая урожайность, так и дифференциация урожая по склону возрастали. Если в 2019 году по сетке 25 га средняя урожайность на площади 82,9 га составила 14,6 ц/га, то в 2020 году на площади 559 га фиксировалась урожайность 18,1 ц/га; в сетке 5 га этот показатель составлял в 2019 и 2020 годах соответственно 16,0 ц/га (площадь 68,3 га) и 18,9 ц/га (65 га); в сетке 1 га - 17,4 ц/га (174,4 га) и 22,6 ц/га (418 га).

На основании сопряженных прецизионных исследований нам удалось выявить причину изменения урожайности по разным частям поля, которая определялась склоном поля и, соответственно, разной степенью влагообеспечености. Здесь можно выделить фактор, связанный с запасом и распределением почвенной влаги, обусловленный особенностью рельефа местности, совокупностью почвенных и гидрологических условий агроландшафта (то есть почвенно-ландшафтно-гидрологических условий). Это 
было реализовано с помощью ДЗ3 и создания цифровой модели рельефа (ЦМР) (31), для чего использовались математические и цифровые модели земной поверхности (32). Чем более детализирован был анализ данных, тем выше оказывалась точность оценки повышения урожайности. Так, прибавка урожайности при детализации по сетке 5 га была чуть меньше $10 \%$, а при сетке 1 га - в 2 раза больше относительно традиционной технологии (по сетке 25 га).

По изменению агроландшафтных условий, определяемых уклоном местности, удалось оценить распределение водотоков, характеризующих запас продуктивной влаги в той или иной части поля (см. рис. 2).

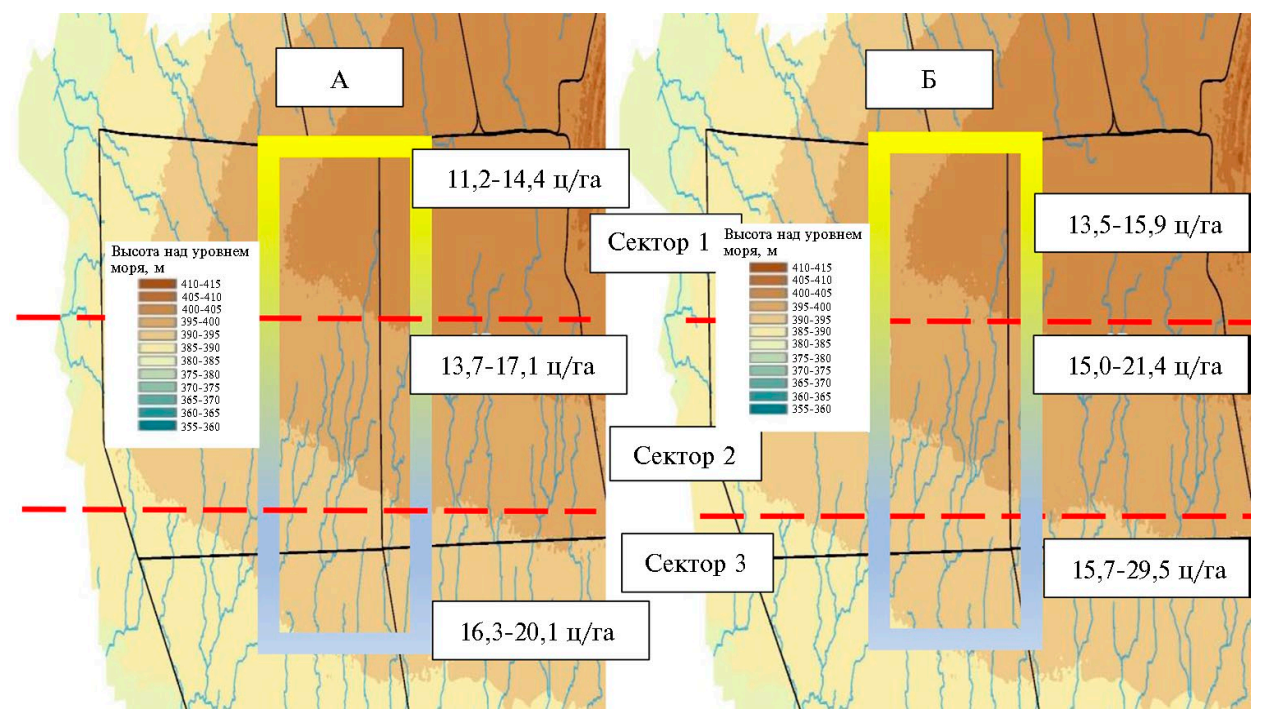

Рис. 2. Распределение урожайности яровой пшеницы Triticum vulgare L. на карте цифровой модели рельефа в разные годы: А - 2019 год, Б - 2020 год. Секторы выделены с координатной привязкой при постоянной долготе $71^{\circ} 02^{\prime} 30.7^{\prime \prime} \mathrm{E}$ с фиксацией высот (h): для сектора 1 $51^{\circ} 33^{\prime} 15.8^{\prime \prime} \mathrm{N}\left(\mathrm{h}=400-405\right.$ м), для сектора $2-51^{\circ} 33^{\prime} 54.7^{\prime \prime} \mathrm{N}(\mathrm{h}=390-395 \mathrm{м})$, для сектора $3-$ $51^{\circ} 32^{\prime} 43.7^{\prime \prime} \mathrm{N}(\mathrm{h}=385-390$ м) (ТОО НПЦ зернового хозяйства им. А.И. Бараева, Казахстан). Прямоугольники в центре изображений А и Б иллюстрируют повышение влагообеспеченности от верхней части рисунка к нижней.
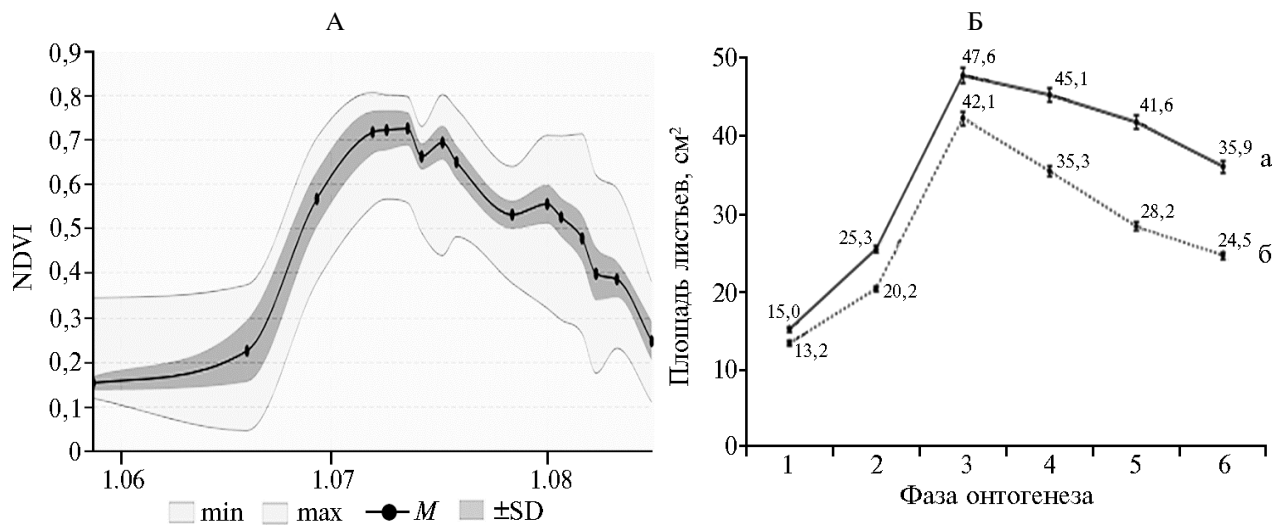

Рис. 3. Соответствие динамики вегетационного индекса по датам (А, данные дистанционного зондирования Земли, ТОО НПЦ зернового хозяйства им. А.И. Бараева, Казахстан, 2019 год) и изменения площади листовой поверхности пшеницы (Б) в онтогенезе в условиях полива (а) и засухи (б) (33): 1 - кущение, 2 - выход в трубку, 3 - колошение, 4 - цветение, 5 - молочная спелость, 6 - восковая спелость.

При оценке динамики развития растений с 26 мая по 10 августа 2019 года было отмечено, что изменение NDVI во времени протекало не- 
равномерно. Постепенное возрастание индекса вегетации с 0,15 до 0,710,73 (6-9 июля) характеризовало нарастание вегетирующей массы и активацию ростовых процессов (рис. 3). Вместе с тем вегетационный индекс не достигал ожидаемых значений 0,9-1,0, что свидетельствовало о недостаточной завершенности физиологических процессов накопления пластичных веществ в растительной биомассе. Последнее могло быть связано с засушливыми условиями, высокими температурами и недостатком влаги, что и не позволило реализовать потенциал возделываемых сортов и агротехнологических решений точного земледелия (33).

Между урожайностью и данными Д33 по индексу NDVI была выявлена корреляция $(r)$ : для сектора $1-0,68$, для сектора $2-0,83$, для сектора $3-0,65$. Но здесь уже проявлялось влияние скорее не агрохимического, а гидрологического фактора, определявшего разницу урожайности по оценочным кластерам.

Также в прецизионных полевых экспериментах было установлено, что при использовании некорневых подкормок растений в разные фазы онтогенеза урожайность пшеницы возрастала с 22,1 ц/га (высокий агрофон) до 22,7-24,7 ц/га, или на 10-20\%. При внесении удобрения Витанолл-NP отмечали статистически значимую (при $\mathrm{HCP}_{05}=3,42$ ц/га) прибавку урожайности 3,7 ц/га, КХМ - 4,1 ц/га, Витанолл-микро - 4,6 ц/га. Эти данные были получены за первый 2019 год исследований. В условиях сезона 2020 года статистически значимых прибавок урожайности за счет применения некорневых подкормок не выявили. В дальнейшем необходимо выяснить особенности и причины неоднозначности этих результатов.

Таким образом, в результате выполненных исследований предложен алгоритм перехода от пассивных мониторинговых мероприятий с использованием дистанционного зондирования Земли (ДЗ3) к активным управляющим действиям, направленным на повышение продуктивности и качества яровой пшеницы в условиях Северного Казахстана. Этот алгоритм основан на использовании ДЗ3 и сопряженных с ними наземных прецизионных измерениях. Он позволяет определить специфику дифференцированного внесения удобрений с учетом отклика растений на изменение индекса вегетации NDVI и управлять физиологическими процессами роста и развития возделываемых культур, что в конечном итоге отражается на повышении урожайности. Так, при Д33 с помощью беспилотных летательных аппаратов (БПЛА) удалось выяснить особенности формирования урожая яровой пшеницы в разных зонах неоднородности поля. При этом такой индикативный показатель, как индекс вегетации NDVI, определяемый с использованием БПЛА, был более информативным, чем спутниковые снимки. С помощью ДЗ3 удалось оценить специфику динамики физиологических процессов в период роста и развития разных сортов пшеницы, выделить критические фазы и определить оптимальные сроки применения корректирующих действий. Значимые прибавки были получены при обработке вегетирующих растений пшеницы раствором Витанолл-NP (1 л/га) в фазы всходов и кущения (на $18 \%)$, KXМ (1 л/га) в фазу кущения (на 19,9 \%) и Витанолл-микро (1 л/га) при комбинированной обработке в фазы кущения, колошения и молочной спелости зерна (на 22,3 \%). Кроме того, с помощью ДЗ3 можно оперативно выявлять зоны депрессии развития растений в неоднородном пространстве поля и своевременно проводить необходимые подкормки. На основании выбранной схемы обработки растений по фазам онтогенеза при использовании средств коррекции урожая (некорневые подкормки) были получены перспективные данные. В целом прецизионное управление продуктивностью 
пшеницы в условиях Северного Казахстана весьма перспективно и требует дальнейшего всестороннего изучения.

\author{
Авторский коллектив выражсает благодарность академику Виктору Петро- \\ вичу Якушеву за помощь в работе над рукописью.
}

\title{
ЛИТЕРАТУРА
}

1. Merchuk-Ovnat L., Fahima T., Ephrath J.E., Krugman T., Saranga Y. Ancestral QTL alleles from wild emmer wheat enhance root development under drought in modern wheat. Front. Plant Sci., 2017, 8: 703-715 (doi: 10.3389/fpls.2017.00703).

2. Araus J.L., Slafer G.A., Royo C., Serret M.D. Breeding for yield potential and stress adaptation in cereals. Critical Reviews in Plant Sciences, 2008, 27(6): 377-412 (doi: $10.1080 / 07352680802467736$ ).

3. Guo Y., Du Z., Chen J., Zhang Z. QTL mapping of wheat plant architectural characteristics and their genetic relationship with seven QTLs conferring resistance to sheath blight. PLoS ONE, 2017, 12(4): e0174939 (doi: 10.1371/journal.pone.0174939).

4. Усков И.Б., Якушев В.П., Чесноков Ю.В. Управление агробиологическими системами физико-агрономические и генетико-селекционные аспекты (к 85-летию Агрофизического научно-исследовательского института). Сельскохозяйственная биология, 2017, 52(3): 429-436 (doi: 10.15389/agrobiology.2017.3.429rus).

5. Panayi E., Peters G.W., Kyriakides G. Statistical modelling for precision agriculture: a case study in optimal environmental schedules for Agaricus Bisporus production via variable domain functional regression. PLoS ONE, 2017, 12(9): e0181921 (doi: 10.1371/journal.pone.0181921).

6. Banu S. Precision agriculture: tomorrow's technology for today's farmer. J. Food Process Technol., 2015, 6(8): 1000468 (doi: 10.4172/2157-7110.1000468).

7. Busse M., Doernberg A., Siebert R., Kuntosch A., Schwerdtner W., König B., Bokelmann W. Innovation mechanisms in German precision farming. Precision Agric., 2014, 15(4): 403-426 (doi: 10.1007/s11119-013-9337-2).

8. Спивак Л.Ф., Терехов А.Г., Витковская И.С., Батырбаева М.Ж. Использование многолетних спутниковых данных различного разрешения для комплексной оценки состояния растительного покрова территории Казахстана. Современные проблемы дистанционного зондирования Земли из космоса, 2009, 6(2): 450-458.

9. Гопп Н.В., Савенков О.А., Смирнов А.В. Цифровое картографирование урожайности яровой пшеницы, выполненному на основе вегетационных индексов и оценка ее изменений в зависимости от свойств антропогенно-преобразованных почв. Современные проблемы дистаниионного зондирования Земли из космоса, 2019, 16(3): 125-139 (doi: 10.21046/2070-7401-2019-16-3-125-139).

10. Roy D.P., Wulder M.A., Loveland T.R., Woodcock C.E., Allen R.G., Anderson M.C., Helder D., Irons J.R., Johnson D.M., Kennedy R., Scambos T.A., Schaaf C.B., Schott J.R., Sheng Y., Vermote E.F., Belward A.S., Bindschadler R., Cohen W.B., Gao F., Hipple J.D., Hostert P., Huntington J., Justice C.O., Kilic A., Kovalskyy V., Lee Z.P., Lymburner L., Masek J.G. McCorkel J. Shuai Y., Trezza R., Vogelmann J., Wynne R.H., Zhu Z. Landsat8: Science and product vision for terrestrial global change research. Remote Sensing of Environment, 2014, 145: 154-172 (doi: 10.1016/j.rse.2014.02.001).

11. Bastiaanssen W.G.M., Noordman E.J.M., Pelgrum H., Davids G., Thoreson B.P., Allen R.G. SEBAL model with remotely sensed data to improve water resources management under actual field conditions. Journal of Irrigation and Drainage Engineering, 2005, 131(1): 85-93 (doi: 10.1061/(ASCE)0733-9437(2005)131:1(85)).

12. Menges R.M., Nixon P.R., Richardson A.J. Light reflectance and remote sensing of weeds in agro-nomic and horticultural crops. Weed Science, 1985, 33(4): 569-581 (doi: $10.1017 / \mathrm{S} 0043174500082862$ ).

13. Thorp K., Tian L.F. A review on remote sensing of weeds in agriculture. Precision Agriculture, 2004, 5(5): 477-508 (doi: 10.1007/s11119-004-5321-1).

14. Diker K., Heermann D. F., Bordahl M. K. Frequency analysis of yield for delineating yield response zones. Precision Agriculture, 2004, 5: 435-444 (doi: 10.1007/s11119-004-5318-9).

15. Комаров А.А., Мунтян А.Н., Суханов П.А. Выбор информативных показателей дистанционного зондирования состояния растительного покрова производственных посевов. Известия СПбГАУ, 2018, 3(52): 64-70.

16. Tahar K.N. Multi rotor UAV at different altitudes for slope mapping studies. International Archives of Photogrammetry Remote Sensing and Spatial Information Sciences, 2015, XL-1/W4: 9-16 (doi: 10.5194/isprsarchives-XL-1-W4-9-2015).

17. Доспехов Б.А. Методика полевого опыта. М., 1985.

18. Aggarwal C., Reddy C. Data clustering: algorithms and applications. CRC Press, Boca Raton, London, New York, 2013: 652. 
19. Ghassempour S., Girosi F., Maeder A. Clustering multivariate time series using hidden Markov models. International Journal of Environmental Research and Public Health. 2014, 11(3): 27412763 (doi: 10.3390/ijerph110302741).

20. Kelley D.R., Salzberg S.L. Clustering metagenomic sequences with interpolated Markov models. BMC Bioinformatics 2010, 2(11): 544 (doi: 10.1186/1471-2105-11-544).

21. Катаев М.Ю., Бекеров А.А., Шалда П.В. Анализ трендов временных рядов вегетационного индекса NDVI. Доклады Томского ГУСУР, 2017, 20(1): 81-84 (doi: 10.21293/18180442-2017-20-1-81-84).

22. Bradley B.A. A curve fitting procedure to derive inter- annual phenologies from time series of noisy satellite NDVI data. Remote Sensing of Environment, 2007, 106(2): 137-145 (doi: 10.1016/j.rse.2006.08.002).

23. Hird J.N. Noise reduction of NDVI time series: An empirical comparison of selected techniques. Remote Sensing of Environment, 2009, 113: 248-258 (doi: 10.1016/j.rse.2008.09.003).

24. Jönsson P., Eklundh L. TIMESAT - A program for analyzing time-series of satellite sensor data. Computers \& Geosciences, 2004, 30(8): 833-845 (doi: 10.1016/j.cageo.2004.05.006).

25. Комаров А.А., Комаров А.А. Перспективы использования комплексных агрохимикатов для дифференцированного их внесения в качестве средств управления ростом и развитием растений. Агрохимический вестник, 2018, 6: 34-38 (doi: 10.24411/0235-2516-2018-10057).

26. Kurtener D.A., Komarov A.A., Krueger E.D., Lavrukov M.Yu, Nayda N.M. Fuzzy multiattributive analyzes of organic-mineral fertilizer "Stimulayf" and "Humate Sodium" application for cultivation of Dracocephalum L. European Agrophysical Journal, 2014, 1(1): 14-24 (doi: 10.17830/j.eaj.2014.01.014).

27. Бекмухамедов Н.Э., Аюпов К.А., Карабкина Н.Н., Дегтярева О.В., Воротынцева В.В. Информационно-аналитическая система АГРОГИС для задач космического мониторинга зернового производства в Казахстане. Мат. четырнадцатой Всероссийской конф. «Современные проблемы дистанционного зондирования Земли из космоса». М., 2016: 328.

28. Терехов А.Г. Оценка влияния незерновых культур на спутниковый прогноз урожайности пшеницы в Северном Казахстане. Современные проблемы дистанционного зондирования Земли из космоса, 2008, 5(2): 371-375.

29. Терехов А.Г. Эмпирические зависимости между элементами продуктивности яровой пшеницы Северного Казахстана и спектральными характеристиками полей по данным EOS MODIS в сезонах 2005-2009. Современные проблемы дистанционного зондирования Земли из космоса, 2010, 7(3): 305-314.

30. Abdullaev K., Irmulatov B., Komarov A., Nugis E. Precision agriculture in the North of Kazakhstan. Journal of Agricultural Science, 2020, 31(2): 115-121 (doi: 10.15159/jas.20.25).

31. Wang L., Liu H. An efficient method for identifying and filling surface depressions in digital elevation models for hydrologic analysis and modelling. International Journal of Geographical Information Science, 2006, 20(2): 193-213 (doi: 10.1080/13658810500433453).

32. Hengl T., Evans I.S. Mathematical and digital models of the land surface. Developments in Soil Science, 2009, 33: 31-63 (doi: 10.1016/s0166-2481(08)00002-0).

33. Лушникова Т.А. Изменение анатомических и физиологических показателей яровой мягкой пшеницы сорта Жигулевская в условиях засухи. Вестник КГУ, 2012, 3: 70-76.

1 ТОО НПЦ Зернового хозяйства им. А.И. Бараева, 021601 Казахстан, Акмолинская обл., Шортандинский район, п. Шортанды-1, ул. Бараева, 1,

e-mail: irmulatov61@mail.ru, tsenter-zerna@mail.ru;

${ }^{2}$ ФГБНУ Агрофизический научно-исследовательский институт,

195220 Россия, г. Санкт-Петербург, Гражданский просп., 14, e-mail: zelenydar@mail.ru $\bowtie$, mail@agrophys.com

Sel'skokhozyaistvennaya biologiya [Agricultural Biology], 2021, V. 56, № 1, pp. 92-102

\title{
PROSPECTS FOR PRECISION MANAGEMENT OF WHEAT PRODUCTIVITY IN THE CONDITIONS OF NORTHERN KAZAKHSTAN
}

\author{
B.R. Irmulatov', K.K. Abdullaev', A.A. Komarov ${ }^{\bowtie}$, V.V. Yakushev²
}

${ }^{1}$ Baraev Scientific-production Center for Grain Farming, p. Shortandy-1, Shortandinsky District, Akmola Region, 021601 Kazakhstan, e-mail irmulatov61@mail.ru, tsenter-zerna@mail.ru;

${ }^{2}$ Agrophysical Research Institute, 14, Grazhdanskii prosp., St. Petersburg, 195220 Russia, e-mail: zelenydar@mail.ru ( $\square$ corresponding author), mail@agrophys.com 
ORCID:

Irmulatov B.R. orcid.org/0000-0002-8155-7817

Abdullaev K.K. orcid.org/0000-0001-7760-4636

The authors declare no conflict of interests

Acknowledgements:

The authors are deeply grateful to Academician Viktor P. Yakushev for insightful comments and suggestions in writing the article.

The work was performed within the framework of the program of the Baraev Scientific-production Center for Grain Farming LLP "Transfer and adaptation of technologies for precision crop production based on the 'Demonstration farms (polygons)' principle in the Akmola region".

Received October 18, 2020

doi: 10.15389/agrobiology.2021.1.92eng

\section{Abstract}

More complete realization of the wheat genetic potential will ensure increasing its yield and quality in the conditions of the Republic of Kazakhstan. Innovative agrotechnological approaches, including a precision farming system (PFS) allow the problem to be addressed. Given the large area of Kazakhstan, the incorporation of precision farming systems needs assessment of the state of its vast territories using the Earth remote sensing (ERS) technology. In this paper, for the first time in the conditions of Northern Kazakhstan, the methods of precision management of spring wheat productivity were implemented. The aim of the work was to assess the prospects for precision farming in the conditions of Northern Kazakhstan and to develop an algorithm not only for passive monitoring of the state of crops, but also for active management of the spring wheat yield using ERS. The field trials were performed on dark chestnut soils in the seasons of 2019-2020 (a special precision farming landfill, Baraev Production Center of Grain Farming) with highly productive spring wheat (Triticum vulgare L.) varieties of local selection, the Shortandinskaya 95 and Astana. At the first stage, the main agrochemical indicators of the test sites were characterized using a ground-based mobile complex. Soil fertility parameters were assessed using survey grids with 1,5 , and 25 ha plot grids. The data were used to identify intra-field heterogeneity and calculate fertilizer doses for differentiated application. The second stage involved crop assessment using images from the Sentinel-2 group satellites and photographs form unmanned aerial vehicles (UAV). Plant development during ontogenesis was characterized by normalized difference vegetation index (NDVI), and the yields were finally evaluated using electronic yield maps. At the third stage, the data were processed using the Stat and Microsoft Excel 2010 software package and AGROS-1 software (version 2.092.11/1993-2009). The main fertilizers were used at sowing and surface applied. Non-root feeding was also performed. Polymer fertilizers Vitanoll-NP (1 l/ha) and Vitanoll-micro (1 l/ha) (Agromarket-24 LLC, Russia), a complex chelated fertilizer CHF (2 1/ha) (Agrophysical Research Institute, Russia), and a humic fertilizer Stimullife $(0.3 \mathrm{l} / \mathrm{ha})$ (Agrofizprodukt LLC, Russia) were used. It was found that only one agrochemical inhomogeneity of the field was partially leveled by the PFS-based differentiated introduction of fertilizers. Soil fertility, landscape profile and hydrological parameters (soil moisture availability) are shown to dominantly affect the spring wheat yield in the arid conditions of Kazakhstan. The changes in the agricultural landscape conditions due to the slope of the terrain, allows us to trace watercourses that characterize the productive moisture availability in a particular part of the field. On the basis of remote sensing data and coupled ground measurements used to precisely assess and record soil, landscape and soil moisture conditions, an algorithm has been developed to manage the yield formation process in plants. It is shown that the more precise the data analysis, the higher the effect of crop yield management. An increase in yield was approximately $10 \%$ for a 5 -ha plot grid and 2 times more for a 1 -ha plot grid. The correlation revealed between the wheat yield and NDVI is strong and uneven as depends on the spatial direction, that is, the $r$ values are 0.64-0.99 along the slope transect and 0.62-0.98 broadwise the field. A significant increase in yield was obtained both due to the differentiated application of mineral fertilizers, by $9.5 \%$ for the 5 -ha grid and by $19.2 \%$ the 1 -ha grid, and due to timely nonroot fertilizing, by $15-22.3 \%$. In general, our findings indicate the PFS prospects in the management of spring wheat productivity under the conditions of Northern Kazakhstan.

Keywords: spring wheat, Northern Kazakhstan, precision agriculture, remote sensing data, agro landscape, soil fertility, soil moisture. 